\title{
Study on Reserved Talents in Competition Sports in Henan Province during the Period of Post-Olympics
}

\author{
Weihua Yao \\ Physical Education College, Luoyang Normal University, Luoyang, Henan, China
}

Received 2012

\begin{abstract}
Utilizing the methods of documentation, questionnaire, and statistics and so on, this paper prosecutes an investigation of the current situation of reserved talents in competitive sports in Henan province to analyze the existing main problems and put forward the proper strategy for development aiming at providing theoretical basis and practice reference for its healthy development.
\end{abstract}

Keywords: Competitive Sports; Reserved Talents; Cultivation

\section{Introduction}

Under the condition of all-round social progress, day-by-day commercialized, professionalizated and scientific world sports circle, how could the cultivating mechanism for sports talents in competitive sports adapt new situation and better realize sustainable development needs to be contemplated, designed and overall planned with wider view. Since Beijing Olympic Games, although the scale of amateur training has been under way, the work point of national sports transferred from competitive sports to mass sports with invisible and formative change of many policies and measures. The change of the form of ownership and organization of amateur training and much contradict caused by the pattern of whole nation which was also unfavorable to the development of sports industry which resulted in the incommensurate problems between reserved talents and social development leading to the decline of the quality of reserved talents. Therefore, to explore the cultivation and countermeasures for development of reserved talents in competitive sports under the background of new era is the meaning of this subject.

\section{Study Methods}

\section{Documentation Method}

The document, books related reserved talents were consulted as well as the papers and material of State Physical Culture Administration and Henan Municipal Sports Administration.

\section{Investigation Methods}

1) Interview method

The related leaders of Henan Municipal Sports Administration, Luoyang Municipal Sports Administration, Jiaozuo Municipal Sports Administration, Nanyang Municipal Sports Administration, the sports school and the coaches was interviewed to gain the related material by the way of visiting and symposium.

2) Questionnaire method

*The project plan of soft science in Henan Provience.(Project Nunmber 112400430077); Teaching reform project in Luoyang Normal University in 2010(Project Nunmber:2010040).
The questionnaires about some closeness and openness problems were designed and questionnaire surveys were undertaken on the related leaders, teachers and coaches to understand the current situation and existing problem of reserved talents.

3) Logical analysis method

The logical knowledge and method was applied to classification, compare and analyze the present material, the questionnaire and this writing.

4) Statistical analysis method

Statistics analysis software SPSS10.0 was applied to deal with the data from the survey.

\section{The Result and Analysis of the Study}

\section{The Survey of the Current Situation of Reserved Talents in Competitive Sports in Henan Province}

1) Lack of resource of reserved talents and low efficiency in the distribution of resources

The main resources of reserved talents come from three aspects. Firstly, the resources come from 11 national high level bases for reserved talents affiliated with sports system, 58 individual training points at the provincial level, 19 training bases at the provincial level, 18 city sports schools, sports school in Henan province which are main fronts[1] With the problems of mutual contradiction among the learning and training and the difficult way out, the number of the students decreased day by day. Lack of reserved talents and low quality of the talents are the outstanding problem existing in the development of sports school. From the view of the cities distribution, there are most reserved talents bases of 11 national high level bases in Zhengzhou (27.27\%). From the view of program layout, the sports of bicycle accounts for most. The data reflects that the reserved talents in competitive sports are tend to centralize to the superior area. However, there are many reserved talents in some programs, but not excellent talents.

Secondly, the traditional sports programs school established together by sports system and education system is the area which could not be ignored to enlarge the scale of reserved talents.13 national traditional sports program school and 253 provincial traditional sports program school were analyzed. The number of the students involved in the training has reach to 
about 37000 which the proportion account for about $7 \%$ of the total number basically reaching the average level.

At last, the resources come from amateur training teams in middle and elementary schools, high level sports teams in college affiliated with education system which are the essential supplementary part. There are ten thousand students in college, middle and elementary school participating extra curricula exercises. However, the influence of social environment, training environment and lack of funds leads to the slow development of competitive sports in school in Henan province. The competitive sports level need to be improved urgently.

The similar programs among each city result in resource consumption with low efficiency in the distribution of resources. To fulfill the sustainable development of competitive sports not only needs plenty of reserved resources but also focus on the internal adjusting allocation of the system to collect resource advantage, reasonably arrange advantaged programs, further to improve the benefit of the allocation of resources.

2) The structure of coach is not reasonable and the scientific training level needs to improve.

The teams of coaches with high quality are the necessary condition for the better development of competitive sports. The situation of sports system has been analyzed due to the adequate professional coaches. The survey shows that the proportion of the coaches under 35 years old accounts for $52.49 \%$ which demonstrates that the team is full of youthful spirit but also means rough task for the training and exercises. The proportion of the coaches with rich experience between 35 and 45 accounts for $28.13 \%$ which little less obviously. The percentage of the coaches with teaching over 11 years accounts for $85.5 \%$ which demonstrates a relative stable coach team in Henan province. Form 1 shows that the coaches retired from specialized teams have rich experience but with low academic level which would influence the further improvement. The coaches have learned from college after retirement with rich practical experience, academic knowledge and best effect of teaching. However, the percentage of this group is too low with unreasonable structure.

Constant improvement of scientific training level is the essential support for the enhancement of sports accomplishment. Scientific training should focus on scientific material, physical training, the recovery of fatigue, psychology training and sporting equipment and so on [2]. However, a large portion of coaches select material according to their experience or recommended by P.E. teachers. Only $29.13 \%$ of the coaches select according to the standard. The creative sense and scientific training level need to be improved.

3) Lack of means to adjust and allocate the resources of competitive sports

The resource investment of the competitive sports at this stage is still mainly from financial appropriation in Henan province. The market mechanism has not yet played its leading

Form 1.

The survey of the source situation of the coaches in sports system in Henan province.

\begin{tabular}{|c|c|c|}
\hline The source of coaches & $\%$ & No. \\
\hline Retired from specialized teams & 35.21 & 1 \\
\hline Graduated from P.E. college & 33.23 & 2 \\
\hline Learned from P.E. college after retirement & 20.30 & 3 \\
\hline Others & 11.26 & 4 \\
\hline
\end{tabular}

role with no good increasing income channel. The transform of the sports resources was used by society, enterprise and individual which is the inevitable outcome of the development of economy. The related policies shoud be enacted and standardized based on the situation of the level of economic development of the local place and the province.

4) The adverse effects of the disadvantage of the competitive system to the transport of reserved talents

With the effect of golden medal-oriented, there are the situation of "fake introduction" with impostors which dampen the grass-roots coaches' enthusiasm and stifle the talents in some cities. In addition, some coaches are enthusing about in low-level contention for championship neglecting the long-term cultivation of reserved talents. Therefore, the problem and unfavorable effect resulting from competitive system should be retested to further perfect the transport and communication of reserved talents.

5) The puzzle existing in the base construction

Firstly, many-layered administration, slow follow-up counterpart funds and obstructed channel of purchase make the devoted funds output slow lacking necessary supervision mechanism. Second, the scale of the training point is too large to take advantage of "the pattern of whole province". Third, the way of "appropriation based on medals" needs to be improved. Forth, the current registration system is unfavorable to the common communication among athletes.

\section{The Strategies of Cultivation of Reserved Talents in Competitive Sports in Henan Province}

1) Set up view of talent to accelerate the overall development of reserved talents.

In the new era of knowledge-based economy, it is more important of possessing high quality human resources than the investment and accumulation of funds, than the possession and expansion of the market with the social focus of the development, cultivation and utilization of the talents [3]. Therefore, the cultivation of reserved talents should be designed and planed from a long-term and broader view to set up new opinion and transfer the way from "training first" to "the combination of knowledge and training" which demands the players take sports on the condition of learning of knowledge.

2) Promote the diversification of the way of the distribution and allocation of resources to optimize the resources of competitive sports

As the subject of the distribution, sports administration at all levels in Henan province take good advantage of sports resources based on the overall condition to attract the various economic subjects to develop programs independently. At present, the current situation of the sports school conducted by government and wushu school conducted by society have represented the reasonable distribution which enhances the application rate of resources to form win-win setup of competitive sports.

Fulfillment of superiority complementary of sports resources could give full play to the maximum efficiency of the limited resources [4]. Based on the planning, the layout of the programs should be considered from the view of sustainable development to ensure the key project group, to reasonably plan the training net with the supports and guarantee of funds and policies, to ensure efficiency of these projects in terms of integration of 
human resources, financial investment and science intervention to achieve the goal of optimal resources. Based on the talent base of individual event at provincial level, Hebi city has developed quickly and has gained 3 gold medals of boxing in the 11th Games. The reasonable layout and optimization of the resources of competitive sports in various cities could not only decrease the consumption of resources but also pursue the maximum benefit.

3) Enlarge the scale of reserved talents by stages, level and points to improve the matriculate quality

Whether in nonprofessional sports school or traditional sports school, there will be the existential crisis with no economies of scale and will be no force of sustainable development with scanty reserved talents [5]. Therefore, the advantage of large population in Henan province should be utilized with better work of popularization to increase the way to create jobs and transfer the population advantage into talent advantage. Firstly, break the state of the scattered reserved talents to improve the talent exchange market. Bring the cultivation into the system of education to enlarge the scale of the teams of reserved talents [6]. Secondly, enlarge the scale of the steady students to improve the matriculate quality depending on the training base of reserved talents in different levels. What's more, "sun-light P.E.", a special activity of school sports in Henan province should be fully utilized to enlarge the scale of reserved talents and broaden the way of athletes, deal with the contradiction between the learning and training.

4) Introduce externally and unite internally to improve the coach training mechanism

Firstly, strengthen post training, build the system of training, create learning organization, strengthen the specific training work to high-end and compound coaches with high-level. Secondly, perfect the talent mobility mechanism, optimize the internal distribution and establish strategic partnership with other provinces to accelerate the communication and cooperation of talent resources, introduce actively competitive mechanism with supports of policy and funds. Thirdly, introduce the famous coaches at home and abroad as consultant to train the athletes regularly whose training level will improve rapidly by the guidance.

5) Gradually reform the current competitive mechanism and strengthen the internal administration

Set up the major sports with secondary sports and take the comprehend test of basic skill and quality at the same time. Pursue registration system strictly to regulate the market and deal efficiently with the relationships of interest among the units and arouse the maximum enthusiasm of the athletes and coaches. Strengthen the internal administration with further efforts of the supervision.

6) Perfect the construction of cultivation system of reserved talents and fulfill the strategic transform of the combination of sports and education.

Build the coordination mechanism of exchange of benefit based on the principle of market and make the cultivation of reserved talents become involved into the system of education, follow the road of the system of education cultivating the competitive talents and fulfill the strategic transform of the combination of sports and education [7]. Accomplish the real fusion of sports and education and gradually build the cultivation system of reserved talents of competitive sports with the specific situation of Henan province.

\section{Conclusion}

The current situation of reserved talents in competitive sports in Henan province seems not to be optimistic. The main existing problems are as follow: the lack of resources of reserved talents; the single means to adjust and allocate the resources; the unreasonable structure of the coaches and the scientific training level needing to be improved; the disadvantage of competitive mechanism influencing the transportation and communication of sports reserved talents; irregular construction and administration of the base and lack of necessary supervision mechanism when using funds. To fulfill the sustainable development needs to set up talent opinion to promote the overall development of reserved talents, to promote diversification of means of resource adjustment and allocation to optimize the competitive sports resources, to enlarge the scale of reserved talents to the point by stages, multi-level to improve the quality of the students, to introduce new resource to perfect the coach training mechanism, to reform recent competitive mechanism, to perfect the construction of system of reserved talents to fulfill the strategic transform with the combination of sports and education.

\section{REFERENCES}

The edition of Physical Culture Development Centre of State Physical Culture Administration. Chinese Sports Yearbook[M], Beijing: Chinese Sports Yearbook Press, 2010.

Zhong Binshu, The Cultivation and Sustainable Development of Competitive Sports Reserved Talents During the Period of Social Transformation [M], Beijing:Beijing Physical Education University Press, 2003.

Yangyang, The Study on Current Situation and Countermeasures for Development of Potential Program of Competitive Sports in Henan Province [D], Southwest Jiaotong University, 2007,6.

Yao Weihua, The Contemplation of the Distribution of Resources of Competitive Sports in Henan Province Duing the Period of Post-Olympics [J], Sports World, 2011,8:31-33.

Yangjun, Lulei, The Analysis of Influence Factors of Sports Reserved Talents in Competitive Sports in Henan Province [J], Sports Journey, 2006,(13)6:121-123.

Yao Weihua, Analysis of the Development Dilemma and Research on the Optimization Strategies of the National Traditional Sport in our Country.2011 International Conference on Information,Services and Management Engineering [C] 2011 International Conference on Information, Services and Management Engineering, 2011(2): 1041.

Gao Songshan, Study on the Current Situation of Competitive Sports in Henan Province and the Countermeasure of the Cultivation of Reserved Talents [J], Sports Science, 2005, (25)2:26-30. 